\title{
Artigos
}

\section{O brincar e o desenvolvimento das noções espaciais na Educação Infantil}

Resumo: $O$ presente estudo se propõe a analisar quais noções espaciais um grupo de crianças da Educação Infantil mobiliza e manifesta ao brincar da "Caça ao tesouro". No processo de elaboração, desenvolvimento e análise das noções espaciais mobilizadas e representadas pelas crianças, reportamo-nos, principalmente, aos estudos de Vygotsky, Leontiev e Wallon. A pesquisa, caracterizada como um estudo de caso qualitativo, foi realizada em uma escola da Rede Municipal de Ensino de Cuiabá- MT, que atende a Educação Infantil e o $1^{\circ}$ Ciclo. Sendo desenvolvida em uma turma da Educação Infantil com crianças na faixa etária de cinco anos. Os dados foram produzidos a partir da observação participante, anotações das pesquisadoras e do registro em vídeo que possibilitou captar o movimento das crianças, as falas, expressões, gestos e emoções. Para fins de análise, os dados foram organizados em um episódio, que, por sua vez, foi dividido em quatro cenas, quais sejam: os conhecimentos prévios manifestos, a primeira leitura do mapa, exploração do mapa coletivamente e a procura ao tesouro. A análise dos dados indica que as crianças mobilizaram noções de posição, direção e sentido e, também, ampliaram sua percepção do espaço.

Palavras-chave: Noções espaciais; Brincadeira; Educação Infantil

\section{The play and the development of the spational notions in the Early Childhood Education}

\begin{abstract}
This study proposes to analyze which spatial notions a group of children of early Childhood Education mobilizes and manifests when playing "Treasure Hunt". The process of elaboration, development and analysis of the spatial notions mobilized and represented by the children, report us, especially, to the studies of Vygotsky, Leontiev and Wallon. The research, characterized as a qualitative case study, was made in a city public school of Cuiabá-MT, which meets the early Childhood Education and the Ist cycle. It was developed in a class of early Childhood Education, with children in the age group of five year olds. The data were made from the participant observation, note taking of the researcher and video records that allowed capturing the children's movement, talks, expressions, gestures and emotions. For analysis purposes, the data were organized in one episode, which was divided in four scenes, which were: previous knowledge manifested, the first reading of the map, collective exploration of the map and the treasure hunt. The analysis of the data indicates that the children mobilized notions of position, direction and sense and also amplified their perception of space.
\end{abstract}

Key-words: Spatial notions; Children's play; Early Childhood Education

\footnotetext{
I Mestranda em Educação na Linha de Pesquisas Educação em Ciências e Educação Matemática do Programa de Pós-graduação da Universidade Federal de Mato Grosso UFMT. Bolsista da Fundação de Amparo à pesquisa do Estado de Mato Grosso - FAPEMAT. E-mail: sueleners@gmail.com

2 Doutora em Educação pela Universidade Estadual de Campinas UNICAMP. Professora do programa de Pós-graduação da Universidade Federal de Mato Grosso. E-mail: rutecristinad@gmail.com
} 
a dinâmica de troca de significados, que permeia a nossa presença no mundo, estamos sempre compartilhando experiências e construindo novos conhecimentos. Este movimento se dá desde o nosso nascimento e acreditamos que o período da infância é a fase em que isso ocorre de maneira intensa e profícua, pois a criança, ao deparar-se com uma cultura constituída historicamente que instrumentaliza a sua ação no mundo, sente-se desafiada a compreendê-la (MOURA, 2007).

Isso implica dizer que, alinhada à concepção de conhecimento dinâmico e histórico, assumimos concomitantemente uma concepção de criança como ser social que se constitui na sua relação com o mundo e com os outros. Nesse sentido, entendemos que a criança, enquanto produtora de conhecimento, está imersa em diferentes ações, desenvolvidas em situações diversificadas que oportunizam o desenvolvimento de diferentes noções, dentre elas as numéricas, as métricas e as espaciais. Evidenciamos, ainda, que estas noções possibilitam-nas resolver problemas do cotidiano e interagir com outras crianças e adultos nos diversos contextos dos quais participam.

Tendo em vista que, na faixa etária do 0 aos 6 anos, este processo de apropriação é desencadeado pela atividade principal da criança, qual seja, o brincar (LEONTIEV, 1991). Destacamos, então, que as propostas pedagógicas devem perpassar necessariamente pela ludicidade.

Compreendemos, que dentre as noções mencionadas acima, as primeiras desenvolvidas pela criança são as espaciais, pois, no decorrer desse período, ela vivencia o espaço e desenvolve-se progressivamente através das relações que estabelece com o mesmo. É a partir destas relações que a criança cria representações simbólicas para o que está a sua volta e, conforme isso acorre, estabelece um vínculo de pertencimento com o contexto social em que está inserida e com seus pares.

Nessa perspectiva, o objetivo deste trabalho foi pesquisar: quais noções espaciais um grupo de crianças da Educação Infantil desenvolve e manifesta ao brincar da "Caça ao tesouro"?

No processo de produção e análise dos dados, pautamo-nos nas relevantes contribuições da psicologia histórico-cultural representada aqui pelas obras de Vigotski (2007), Leontiev (1991, 1991a) e da psicologia genético-dialética abordada por Wallon $(1975,1981)$.

Nesse trabalho apresentamos, inicialmente, uma discussão sobre a atividade do brincar para, 
em seguida, tratar das concepções relativas às noções espaciais que nortearam a investigação. Descrevemos na seqüência a proposta desenvolvida, a metodologia da pesquisa e por fim a análise dos dados produzidos e nossas considerações.

\section{O brincar como atividade principal da criança}

Vigotski (2007) destaca que ao brincar a criança tem a oportunidade de vivenciar diversos papéis e elaborar diferentes relações, pois, por meio desta atividade, ela dialoga como o mundo, imitando situações e habilidades que superam suas capacidades, apropriando-se das formas de agir do adulto e ampliando os instrumentos que tem para se relacionar com mundo.

O mesmo autor compreende que a criança reproduz e representa o contexto em que está inserida por meio das situações vivenciadas e das brincadeiras. Contudo, tal reprodução não se faz passivamente, mas mediante a um processo de reinterpretação do mundo, que abre lugar para a invenção e a produção de novos significados, saberes e práticas (VIGOTSKI, 2007). Ou seja, no brincar ela cria, imagina, interage, interpreta, se expressa e, nessas relações multifacetadas, imprime o mundo em si ao mesmo tempo em que se imprime nele.

Conforme já mencionado no início deste trabalho, para Leontiev (1991) é através da atividade de brincar que a criança se relaciona com o contexto em que está inserida e internaliza novos conhecimentos e, por esse motivo, o autor a considera como sua atividade principal.

Destacamos ainda que Leontiev (1991) denomina como "atividade" toda ação impulsionada por uma necessidade específica. Para este autor, o ser humano é movido por suas necessidades e estas, por sua vez, impulsionam os motivos. A partir das necessidades e dos motivos, surgem ações ou grupos de ações que atenderão a procedimentos de realização denominados de operações. Essas ações estão relacionadas ao objetivo que se deseja alcançar, ou seja, o objeto da ação. E os objetivos, nesse contexto, estão estreitamente relacionados aos seus motivos. Este movimento é denominado pelo autor como atividade e é considerado como móvel desencadeador da produção do conhecimento humano.

Para Leontiev (1991), a criança não tem um motivo específico para brincar, ou melhor, a própria brincadeira é o motivo. É certo que tudo que articulamos até agora nos leva a pensar na função objetiva da brincadeira, enquanto mediadora da apropriação da realidade pela criança, mas para ela o motivo que a leva a brincar é a própria brincadeira. Ou seja, para a criança a brincadeira tem a sua finalidade nela própria, pois “o jogo não é uma atividade produtiva; seu alvo não está em seu resultado, mas na ação em si mesma" (LEONTIEV, 1991, p. 122).

Contudo, para este autor, a brincadeira é a atividade principal da criança, justamente por ser a 
atividade que se revela como móvel de ampliação das funções psicológicas superiores, ou seja, por ser mobilizadora de aprendizagens e desenvolvimento. Apesar de ambas as afirmações à primeira vista parecerem antagônicas, não o são na perspectiva do autor, pois ainda que a brincadeira tenha a sua finalidade em si mesma e a criança não tenha uma intenção definida de aprender através dela, este fato ocorre sem que seja previsto por ela, pois, ao brincar, ocorrem transformações psicológicas e sociais que a afetam e modificam. Na perspectiva da criança, brinca-se pelo ato de brincar; no entanto, na perspectiva de quem a observa, enquanto estudioso do seu processo constitutivo, o brincar é claramente móvel de ampliação das possibilidades cognitivas.

Partindo deste pressuposto e nos pautando nas observações de Elkonin (1987) sobre a importância da mediação do professor nesse processo, consideramos que consistem em brincadeiras não somente as que se desencadeiam livremente na interação entre as crianças, mas também aquelas propostas na interação entre as crianças e o professor, tendo em vista uma intencionalidade pedagógica que apenas este último deve conhecer.

Compreendemos assim que dependerá do professor e da sua mediação e interação com as crianças manter a especificidade da brincadeira, não permitindo a sua descaracterização. Os objetivos pedagógicos podem coexistir com o ato de brincar, desde que estes não o destituam das representações simbólicas que lhes são características nessa faixa etária, garantindo à criança a possibilidade de criar e se manifestar livremente.

Ao brincar, a criança se movimenta no espaço, se descobre, explora os objetos, cria e recria o ambiente, aspectos que abordamos a seguir.

\section{Corpo, movimento e espaço: uma relação interdependente}

As noções espaciais estão intrinsecamente ligadas aos conceitos geométricos, tendo em vista que a geometria, em grande parte, consiste na representação ideal das formas encontradas nos objetos dispostos no espaço real.

Nessa perspectiva, em consonância com a teoria histórico-cultural,

trabalho envolvendo espaço e forma não deve limitar-se ao
reconhecimento e à memorização de formas geométricas. Há que
desenvolver propostas que considerem o espaço sob a perspectiva do
esquema corporal, da percepção do espaço, além das noções
geométricas propriamente ditas (ARAÚjO, 20 I0, p. I65).

Evidenciamos ainda que a compreensão, a organização e a representação do espaço pressupõem o conhecimento deste e o reconhecimento do seu lugar no mesmo, assim como a capacidade de orientar-se nele. 
Localização, posição, direção e sentido são elementos que compõe a orientação espacial e que nos instrumentalizam a entender este espaço e atuar sobre ele. A elaboração destes elementos desencadeia-se na criança a partir da exploração do espaço pelo movimento, ou seja, através do corpo. O desenvolvimento do pensamento geométrico se inicia com base nas experiências objetivas e perceptivas desencadeadas na relação com o espaço, sendo que essa relação permeia o próprio desenvolvimento da criança.

Inicialmente isso acontece por meio da descoberta do próprio corpo e das possibilidades de manifestação deste no espaço. Andar, correr, pular, pegar ou lançar objetos são ações que mediam a relação das crianças com o espaço e é a partir dessas ações que elas o significam e transformam.

Wallon (1975) destaca que a compreensão e a representação do espaço estão diretamente ligadas ao desenvolvimento do esquema corporal e da imagem corporal, o corpo, assim, encontra-se vinculado ao espaço e é a partir dele que desenvolvemos as primeiras noções de orientação espacial.

O referido autor traz como pressuposto que a criança, nos primeiros anos de vida, tem uma visão sincrética do mundo, ou seja, ela não se percebe separada do mesmo. Tudo que ela vê ou toca, todos os objetos a sua volta fazem parte de um conjunto indissociável no qual também está incluída. O processo de separação ou dissociação que acontece progressivamente com a criança enquanto se relaciona com o meio e com seus pares, Wallon (1975) denomina de diferenciação.

Conforme o autor, a diferenciação consiste em identificar-se como ser separado e independente do espaço e dos objetos que o constitui, concomitantemente, reconhecendo-se enquanto corpo nesse espaço, agindo sobre ele e modificando-o. Este é o primeiro passo para desenvolver uma imagem de si, identificando seu próprio corpo e as partes que o compõe, o que é chamado de imagem corporal.

No entanto, para determinar e controlar sua ação no espaço, para além do desenvolvimento da imagem corporal, a criança precisa também conhecer e controlar as suas próprias possibilidades motoras, o que consiste na elaboração do esquema corporal, que segundo Wallon (1975, p.124) “é o resultado e a condição de justas relações entre o indivíduo e o meio". Ou seja, conforme este autor, reconhecendo-se enquanto corpo no espaço, a criança desenvolve uma relação com este através da ação, mediante os limites e as possibilidades motoras que já desenvolveu.

Para desenvolver essa relação, também são elementos importantes a lateralidade e a dominância lateral. A lateralidade consiste na independência dos dois lados do corpo (esquerdo e direito), ou seja, a capacidade que temos de executar diferentes ações utilizando-os separadamente. E a dominância lateral configura-se na maior utilização de um desses lados para desenvolver tarefas cotidianas como desenhar, escrever ou segurar os talheres no momento da alimentação.

Tendo em vista a discussão até agora apresentada, concebemos que orientar-se no espaço 
prevê reconhecer-se como um corpo separado deste, desenvolvendo uma imagem corporal de si mesmo. Este é o primeiro passo para a percepção das manifestações do corpo no espaço, constituindo gradualmente o esquema corporal.

Conforme aponta Lurçat (1979), este processo está vinculado ao reconhecimento da divisão do corpo em quadrantes direita/esquerda, frente/atrás e à percepção da sua projeção no espaço, pois é através desta que as crianças estabelecem relações como posição, localização, direção e sentido. E estas relações são interdependentes, se entrelaçando numa perspectiva de complementariedade e, por sua vez, compõem o repertório necessário para a organização da orientação espacial.

Quando falamos de posição, pensamos num objeto parado em determinado lugar do espaço, o que nos leva a compreender esta relação como um ponto ou local específico que um objeto ocupa. Enquanto que a localização consiste na relação desta posição com outros referenciais, a partir dos quais podemos nos orientar para encontrar este mesmo ponto. Localizar algo num determinado contexto espacial significa, então, desvelar a sua posição, a partir de outros objetos.

A localização está também relacionada à direção e aos sentidos de um ponto em relação aos pontos de referência e em relação a nós mesmos, pois consideramos aqui a direção como a linha que une dois pontos e o sentido e a orientação dessa direção, sendo esta baseada nos quadrantes anteriormente citados: frente/atrás, esquerda/direita.

Ainda que estas noções sejam genuinamente intuitivas a princípio, elas consistem na base para o desenvolvimento das noções espaciais e, posteriormente, para o pensamento geométrico.

Partindo deste pressuposto, acreditamos que este processo perpassa pela ampliação das noções elaboradas no dia-a-dia a partir dos constantes desafios que o meio impõe à criança. E isso prevê uma comunicação com o espaço, atribuindo significados aos objetos e às situações de deslocamento.

Nesse sentido, para que a criança desenvolva e amplie estas noções, precisará explorar o espaço, mover-se nele e organizá-lo, vivenciando-o para que tenha elementos que a instrumentalizem a representá-lo. O corpo tem um papel fundamental neste processo, pois ele é a primeira ferramenta utilizada para manifestar-se no mundo e apropriar-se do mesmo, sendo que esse movimento desencadeia-se a partir da atividade do brincar.

A partir dessas considerações, entendemos que pensar práticas pedagógicas que privilegiem a apropriação das noções espaciais na Educação Infantil consiste em elaborar e planejar atividades que oportunizem o movimento a partir do lúdico e do jogo simbólico, disponibilizando à criança situações em que precise mover-se e orientar-se no espaço, percebendo as particularidades deste enquanto o faz.

É nessa perspectiva que desenvolvemos a proposta da brincadeira da "Caça ao Tesouro" da 
qual trataremos a seguir.

\title{
ABrincadeira da "Caça ao Tesouro": pensando sobre o espaço
}

No intuito de responder ao nosso problema, desenvolvemos o planejamento de uma atividade de intervenção que consistia na brincadeira da "Caça ao Tesouro".

Utilizamos, como desencadeador da atividade, a história "Caça ao tesouro no Sítio". Adaptação baseada em episódios da série televisiva Sítio do Pica Pau Amarelo, conforme o enredo abaixo:

\begin{abstract}
Lá no Sitio do Pica-pau Amarelo Pedrinho, Narizinho e Emília aprontam as maiores confusões e brincam de tudo: amarelinha, pular corda, empinar pipa, bolinha de gude, pega-pega e esconde-esconde. Eles brincam juntos todos os dias até cansar de tanto brincar, depois começam tudo de novo.

Um dia quando eles menos esperavam, apareceu por aquelas redondezas um pirata, o primeiro a vê-lo foi o Saci, que foi correndo (pulando) contar ao Pedrinho. $\bigcirc$ menino se escondeu na mata para descobrir o que o pirata queria e viu que ele carregava um baú do tesouro e procurava um lugar para escondê-lo. Pedrinho não pensou duas vezes e começou a segui-lo, só que o pirata não era bobo não! Ele estava fugindo há muito tempo, tentando esconder o seu tesouro, e percebeu que tinha alguém por perto.

Vendo que não poderia esconder seu tesouro com segurança ali, usou seu medalhão mágico e abriu uma porta que o levaria a outro lugar mais seguro. Sabe onde ele foi parar? Aqui na nossa escola. Então, ele escondeu o seu tesouro para que nem Pedrinho nem outros piratas o encontrassem. Onde será que o pirata escondeu seu tesouro? Será que poderíamos encontrá-lo? Ah! O pirata muito esperto desenhou um mapa para não esquecer onde tinha escondido seu tesouro, só que, na pressa de fugir, deixou-o cair. Se nós tivéssemos o mapa do pirata poderíamos encontrar o tesouro que ele escondeu? Vejam! $\bigcirc$ mapa está aqui! Então, vamos procurar o tesouro do pirata?
\end{abstract}

Optamos pela história, como mobilizadora da atividade, no intuito de utilizar o jogo simbólico para potencializar o interesse das crianças pela brincadeira, promovendo uma interação com os personagens e gerando uma necessidade específica: a de encontrar o tesouro. Nossa intenção, neste momento, era desencadear a necessidade e os motivos, dando elementos para que as crianças se colocassem em atividade (LEONTIEV, 1991).

Também baseando-nos nas potencialidades do jogo simbólico, utilizamos uma dinâmica de caracterização das crianças como piratas, vestindo-lhes com lenços e tapa-olho, criando a sensação de pertencimento e coautoria na história.

Além dos elementos acima citados, a atividade teve como elemento mediador das relações espaciais o "Mapa do Pirata” apresentado na Figura 1 abaixo. 


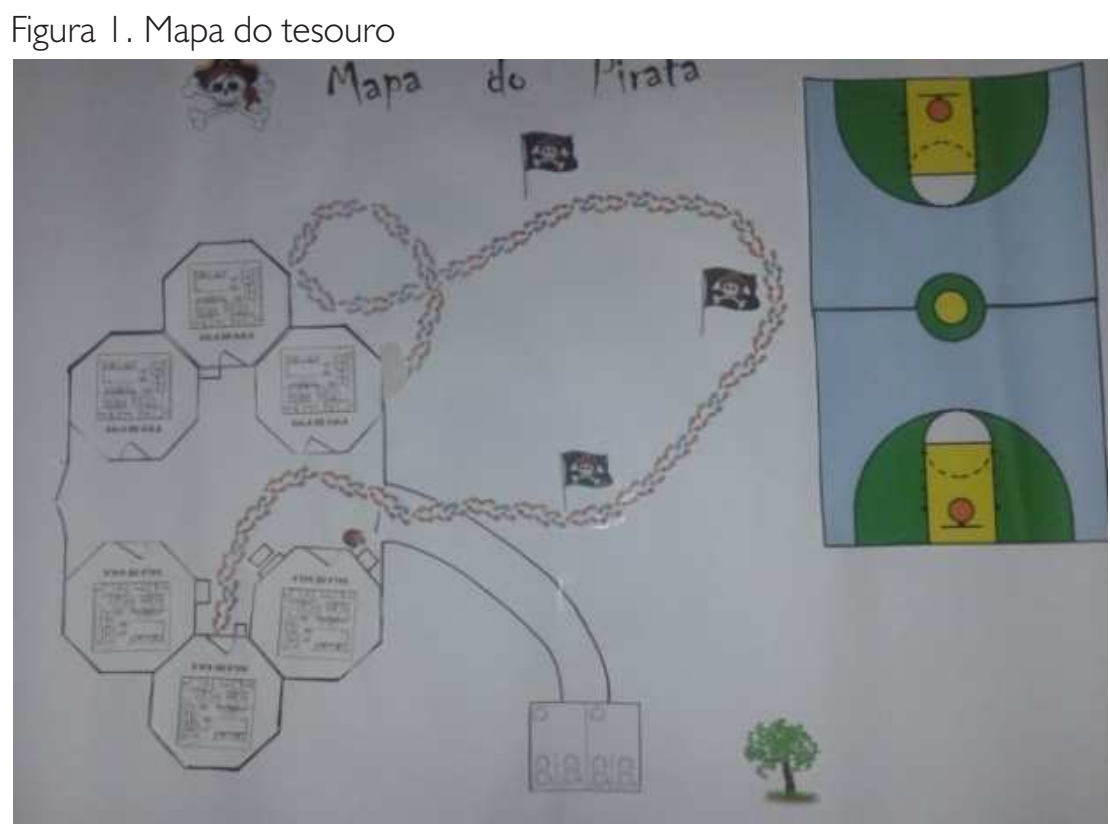

Fonte: Arquivo das pesquisadoras.

A utilização do mapa tinha como principal objetivo, através do jogo simbólico associado ao deslocamento, levar as crianças a identificarem pontos de referências, situando-se e movimentandose nos espaços mediados pelas instruções visuais contidas no mapa.

Para respondermos a nossa pergunta de investigação, seguimos o percurso metodológico que descreveremos a seguir.

\section{Percurso metodológico}

A nossa pesquisa buscou compreender as manifestações de um fenômeno: o desenvolvimento e a manifestação das noções espaciais. O contexto era uma sala de aula da Educação Infantil, caracterizando-se assim como um estudo de caso qualitativo.

Partimos das ideias de Stake (2012, p. 58) que aponta, enquanto características marcantes da pesquisa qualitativa, a busca pela compreensão ao invés da explicação, a presença interpretativa do pesquisador e a ênfase ao tratamento holístico dos fenômenos. $\mathrm{O}$ autor destaca que nesta perspectiva a pesquisa qualitativa "se afasta da explicação de causa e efeito e se aproxima da interpretação pessoal"'.

Concordamos ainda com González Rey (2010, p. 5) que partir dessa abordagem “implica compreender o conhecimento como produção e não como apropriação linear de uma realidade que se nos apresenta".

A pesquisa foi realizada em uma escola da Rede Municipal de Ensino de Cuiabá- MT, que atende a Educação Infantil e o $1^{\circ}$ Ciclo, sendo desenvolvida em uma turma da Educação Infantil com 
crianças na faixa etária de 5 anos.

O processo de coleta de dados ocorreu em momentos distintos, porém complementares, sendo estes:

- reuniões para conversar sobre a proposta e o desenvolvimento da atividade com a professora regente da sala de aula;

- desenvolvimento da atividade pelas pesquisadoras com o acompanhamento da professora;

- discussão sobre a atividade desenvolvida com as crianças.

Os dados foram produzidos (GONZÁLEZ REY, 2010) a partir da observação participante, anotações das pesquisadoras e do registro em vídeo que possibilitou captar o movimento das crianças, as falas, expressões, gestos e emoções.

Para fins de análise, os dados foram organizados em um episódio que, por sua vez, foi dividido em quatro cenas.

Consideramos aqui como um episódio, as ações relativas às noções espaciais mobilizadas, desenvolvidas e manifestadas pelas crianças, que participaram da brincadeira da "Caça ao Tesouro", e que contribuíram para responder nosso problema de investigação (LANNER DE MOURA, 1995). Sendo estas cenas ações específicas que ilustram diferentes momentos do movimento das crianças na brincadeira, quais sejam: os conhecimentos prévios manifestos, a primeira leitura do mapa, exploração do mapa coletivamente e a procura ao tesouro.

\section{Episódio: A "Caça ao tesouro"}

Em consonância com os referenciais discutidos, acreditamos que o trabalho na Educação Infantil envolve intencionalidade e planejamento, o que implica conhecimento específico, metodológico e das características e especificidades da infância. A proposta, apresentada e desenvolvida, intentou articular estes elementos e a opção pela história como desencadeadora coaduna com estes objetivos, além de promover uma situação em que as crianças puderam imaginar e criar numa interface com o lúdico.

Nesse sentido, evidenciamos que a história não só despertou o interesse e mobilizou a atenção das crianças, mas também desencadeou a necessidade de atuar como partícipe da história, despertando-lhes os motivos para a busca do tesouro. O que nos respalda para afirmar que a contação da história atingiu os seus objetivos, visto que as crianças mostraram-se atentas e participativas, foram os comentários sobre particularidades dos personagens que já conheciam enquanto manuseavam os fantoches conforme estes passavam nas mãos das crianças na roda.

No entanto, a situação que melhor ilustra a nossa afirmativa anterior é quando chegamos ao 
clímax da história, revelando que o pirata tinha se deslocado até a escola onde as crianças estavam. Elas, neste momento, manifestaram o seu envolvimento na atividade, pois houve um misto de empolgação geral e ansiedade. O mesmo ocorreu quando o mapa foi revelado e no momento em que as caracterizamos de piratas para procurar o tesouro.

Nessa perspectiva, o envolvimento desencadeado pelo jogo simbólico pontencializou a dimensão lúdica da atividade fazendo com que a própria história se constituísse enquanto parte da brincadeira.

A história gerou a necessidade de achar o tesouro e com isso estabeleceu o motivo, que estava relacionado com a própria curiosidade das crianças em descobrir qual era o tesouro e tomá-lo para si. As ações e operações desencadeadas a partir disso consistiram na brincadeira da "Caça ao Tesouro" e o envolvimento das crianças na referida brincadeira caracterizou-a como atividade (LEONTIEV, 1991).

Configuramos, a partir deste episódio, quatro cenas a seguir destacadas:

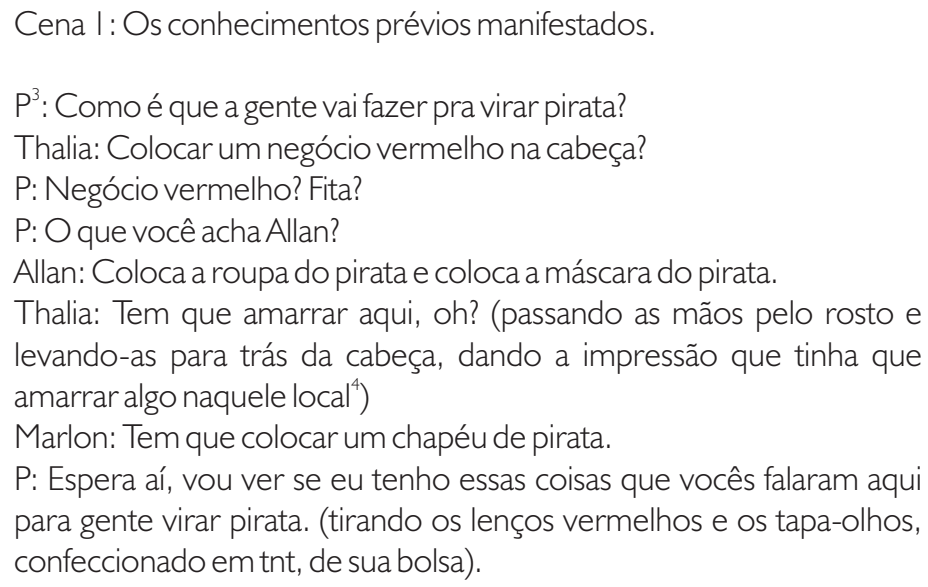

$\mathrm{Na}$ cena 1, percebemos que as crianças interagem e estabelecem relações a partir de elementos que compõe o seu acervo cultural, atribuindo significados e sentidos a objetos, situações e papéis socialmente construídos.

Quando Thalia indica que existe um adereço que o pirata usa e que este deve ser amarrado na cabeça do personagem ou quando Allan aponta que o pirata usa uma roupa específica e um chapéu, percebemos que eles trouxeram estes conhecimentos do seu contato com o personagem através de histórias, filmes ou imagens, que sugere uma apropriação do acervo cultural da humanidade.

Consideramos que essas noções, que as crianças trazem consigo, desenvolvem-se nas relações com seu entorno e se constituem mediadas pelo contato com a mídia e nas relações 
estabelecidas nos locais de convivência ou instituições sociais que frequentam, entre elas a escola.

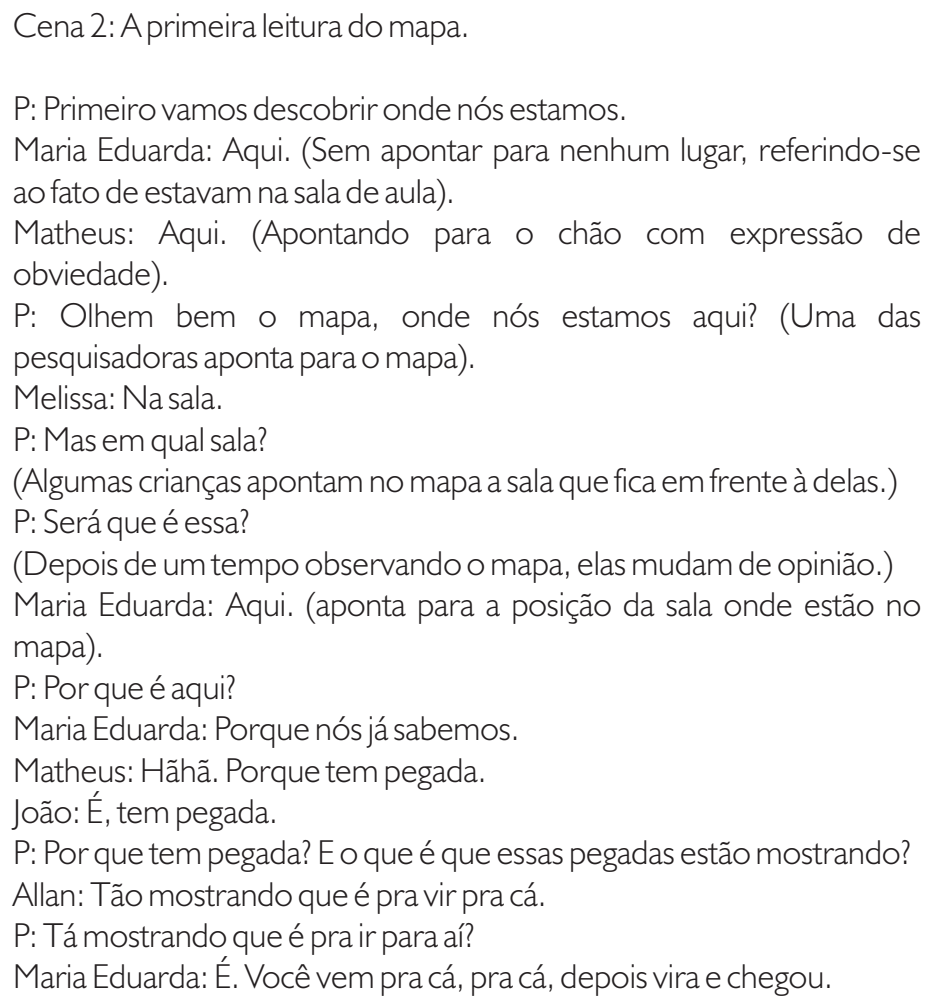

A cena 2 corresponde ao momento em que o mapa é revelado e diz respeito, especificamente, a esse primeiro contato das crianças e as hipóteses de posição e localização que elas levantaram no decorrer dessa leitura inicial.

No início, as crianças demonstraram dificuldade em perceber a sua posição no mapa, contudo, chamadas a observar mais atentamente, foram desvelando, gradualmente, no diálogo como as pesquisadoras e as outras crianças referências que poderiam auxiliar a descobrirem onde estavam.

No decorrer desse processo, elas perceberam, ainda que intuitivamente, que para utilizar o mapa como instrumento para encontrar o tesouro precisavam primeiramente definir de onde partiriam, o que implicava determinar sua posição e a partir dela localizar-se no contexto que o referido mapa apresentava.

A estratégia que elas elaboraram para isso estava relacionada tanto aos seus conhecimentos prévios no que se referia 'aos mapas' quanto à própria noção que tinham do corpo como referência para o deslocamento e reconhecimento do espaço. As crianças perceberam em qual sala de aula estavam através das pegadas que partiam desse local. E, assim, elas determinaram não somente a sua posição, como também as primeiras referências e indicativos de direções a seguir.

Destacamos também, como elemento importante nesta cena, a linguagem utilizada para se referir ao percurso que deveriam fazer da sala até chegar ao tesouro, que se caracterizou 
essencialmente pelo uso de advérbios de lugar quando se referiam às direções que deveriam tomar. Também se evidenciou a compreensão do corpo como elemento fundamental de exploração e apropriação do espaço, quando as crianças utilizaram os dedos para traçarem no mapa o caminho que fariam até chegar ao local onde estava o tesouro.

Cena 3: Exploração do mapa coletivamente.

P: Então, onde nós estamos mesmo?

$C^{5}$ : Na nossa sala.

P: Nós temos que sair da nossa sala e depois que a gente sair da nossa sala nós vamos pra onde?

João: Pra...(Pensando)

Maria Eduarda: Para o banheiro.

Matheus: Pra cá. (Apontando a figura do Baú no mapa).

Bryan: Pro baú.

P: Mas onde que as pegadas estão indo. De onde que elas saíram?

C: Daqui. (Apontando o local no mapa).

P: Elas saíram daqui e foram pra onde?

Bryan: Pra cá, pra cá e pra cá. (Fazendo o percurso com o dedo).

P: Então, nós saímos daqui da sala (mostrando a posição no mapa).

Essa saída daqui, oh, aqui nós estamos saindo da escola (apontando no mapa o portão onde as pegadas levavam), essa saída daqui é a saída da frente ou a saída dos fundos da escola?

Allan: Do fundo.

P: Eo que tem aqui?

Brayan: Bebedouro (olhando a figura de uma menina bebendo água no mapa).

P: Então, primeiro nós saímos daqui (apontando a posição no mapa), fomos por aqui (seguindo as pegadas com o dedo) e chegamos, onde? C. Bebedouro.

P: Aqui perto do bebedouro, tem um portão, não tem? Depois desse portão a gente foi até a onde?

Allan: Aquiiii (mostrando o caminho das pegadas com o dedo).

P: Mas aqui tem uma marcação, o que é isso aqui? (mostrando a figura da bandeira do pirata)

Allan: Bandeira do pirata.

P: Ah? É uma bandeira do pirata. Ela tá mais perto do banheiro ou mais perto da quadra?

Maria Eduarda: Mais perto do banheiro.

P: Mais perto do banheiro? Mas e depois daqui nós fomos até onde? Qual é a próxima marcação?

João: Até aqui oh... (mostrando a segunda bandeira)

Allan: Bandeira.

P: Tem outra bandeira, a segunda bandeira. E essa bandeira está mais próxima do banheiro ou mais próxima da quadra?

Thalia: Não. Tálonge...

Allan: Tá longe do banheiro e tá perto da quadra.

P: Eagora, nós vamos pra onde?

Thalia: Pra essa (apontando no mapa a terceira bandeira), essa outra bandeira. 
$\mathrm{Na}$ cena 3, conforme acompanhamos o diálogo entre as pesquisadoras (que aqui representam o papel de mediadoras da atividade) e as crianças sobre o mapa, percebemos que, ao serem questionadas, estas mobilizaram-se no grupo para compreendê-lo, localizando os pontos de referência que ele apresentava, ampliando, assim, a sua leitura inicial. Nessa cena, evidenciou-se o papel do professor como mediador de aprendizagens, levando em consideração que esse movimento de ampliação das noções já apropriadas pelas crianças é potencializado pelo questionamento e pela exploração das possibilidades que são propostas ao grupo.

No que diz respeito às noções espaciais, percebemos que elas manifestaram indicações de posição e direção. No entanto, utilizando ainda na maioria das vezes a linguagem corporal, apontando para a direção que deveriam tomar ou para o chão quando queriam indicar a sua posição atual. Esta observação remete a necessidade de explorarmos tanto a linguagem matemática para que a criança dela se aproprie paulatinamente; quanto as noções de sentido (esquerda/direita) e direção (para frente/para trás).

Além disso, percebemos também que as crianças demonstraram uma proximidade maior com os termos que indicavam distância (longe/perto) e os utilizavam com fluência e segurança.

\section{Cena 4: A procura ao tesouro.}

Depois da leitura do mapa, partimos para a busca do tesouro, utilizando-o como apoio. Durante os primeiros momentos, a turma andou em grupo e foram conversando sobre a atividade e contando os passos com as pesquisadoras, apesar de não se mostrarem interessados nesta ação em particular. Estavam focados no seu objetivo, que era achar o tesouro.

Ao chegarmos ao bebedouro, primeiro ponto de referência do mapa, nos reunimos para olhar o mapa novamente. Neste momento, as crianças já haviam localizado visualmente a primeira bandeira. Maria Eduarda é a primeira que sinaliza a sua localização: "Tem uma bandeira bem ali." Ela diz toda animada. Assim, fomos em direção a ela. Paramos então para olhar o mapa novamente, quando Thalia aponta para a próxima bandeira e diz: Tem mais uma! Referindo-se à próxima bandeira. Perguntamos às crianças onde estávamos no mapa e onde deveríamos ir? No que Maria Eduarda responde: Nós já chegamos numa. Referindo-se a bandeira que segurava. E Allan completa: Aí a gente vai pra aquela outra. (apontando na direção da próxima bandeira) e aí depois a gente vai pra aquela outra lá (apontando a terceira bandeira).

A partir daí, o grupo começou a se dispersar, pois alguns queriam correr na frente e chegar logo na terceira bandeira. Nesse momento as crianças não queriam mais observar as orientações do mapa, mas queriam chegar às referências já observadas nele anteriormente e, consequentemente, ao tesouro. Contudo, ao chegarmos a terceira bandeira, não havia mais pontos de referência visíveis, então todos se reuniram em volta do mapa novamente.

Como no esquema visual do mapa havia um movimento circular com as pegadas para chegar ao tesouro, isso se constituiu em uma informação que as crianças não atribuíram significado e começaram a 
dar a volta no prédio da escola em busca do local onde estava o tesouro.

Nesse momento, a empolgação das crianças foi maior do que a vontade de pensar sobre a sua localização. A necessidade de se movimentar livremente no espaço para reconhecê-lo se manifestou e, depois de algumas explorações, finalmente eles encontraram o tesouro.

No entanto, antes de encontrarem o tesouro, as crianças contornaram o prédio da escola, enquanto procuravam por indícios que os levassem até ele, mencionando algumas vezes as bandeiras do pirata. Nesse momento, eles correram, pularam, nomearam os locais por onde passaram e conversavam animadamente sobre a atividade. Quando chegamos novamente ao ponto onde estávamos, uma das crianças localizou o ' $x$ ' que demarcava onde o tesouro se encontrava a alguns passos de nós. Etodos se dirigiram eufóricos para o local.

Ao retornamos para a sala com o baú, a alegria era geral. Todos pulavam e gritavam animados. Antes de abri-lo, porém, retomamos a discussão sobre o eles achavam que tinha dentro dele e até passamos o baú na roda para sentirmos o seu peso. As crianças, contudo, não ficaram desapontadas com o tesouro, pois o baú estava cheio de balas e pirulitos que foram repartidos entre o grupo com muita animação.

Na cena 4, optamos por analisar o diário de campo das pesquisadoras para destacarmos o movimento das crianças durante a brincadeira desenvolvida.

A partir das considerações apresentadas pelas anotações do diário, percebemos como a relação entre o corpo e o espaço esteve constantemente presente, pois o objetivo da atividade era a orientação no espaço através da mediação do mapa, o que, de um modo geral, ocorreu. Em determinado momento da atividade, quando as crianças chegaram ao movimento circular feito pelas pegadas e não encontraram no mapa recursos para orientá-las, o que prevaleceu foi à exploração livre.

Consideramos relevante destacar que as crianças, no decorrer da atividade, identificaram as bandeiras do pirata como pontos de referência, o que se evidencia quando Maria Eduarda percebe a primeira bandeira e, a partir daí, mobiliza outras crianças na busca pelas bandeiras. Neste momento, como aponta o diário das pesquisadoras, a consulta ao mapa foi esquecida e retomada apenas quando não haviam mais bandeiras à vista.

Também a mediação do jogo simbólico, ou como diz Moura (2010) o jogo protagonizado, teve um papel muito importante na mobilização das crianças para o desenvolvimento da atividade, sendo que a partir dele constituíram-se elementos desencadeadores para a busca pelo baú do tesouro. Elementos que permearam toda a atividade.

\section{Algumas considerações}

Pensando nas crianças como seres singulares, que atuam ativamente na apropriação e produção de conhecimento de forma individual e coletiva e, no conhecimento matemático enquanto 
produção humana, contextualizada historicamente, acreditamos em uma abordagem dialógica no que diz respeito ao trabalho com a matemática na Educação Infantil, baseada na valorização das experiências e saberes das crianças.

Entendemos ainda que as crianças percebam o espaço como um todo indissociável, uma imagem única da qual elas fazem parte, ou seja, têm uma visão sincrética do mundo. Contudo, conforme elas têm oportunidades de interagir com esse espaço, passam gradualmente a perceberemse nele, reconhecendo-se enquanto seres separados desse espaço e dos objetos que o compõe. Concomitantemente começam a perceber que, apesar daquele espaço ser um conjunto na sua totalidade, ele é composto por objetos que tem forma, tamanho, cores, entre outras características e passam a compará-los, diferenciá-los e a orientarem-se a partir deles. O que representa um grande avanço, pois é neste momento que começam a desenvolver possibilidades de representação mais aproximadas com a realidade desse espaço.

Nesse sentido, tomamos como prerrogativa que as noções espaciais constituem um acervo de conhecimentos, do qual as crianças, enquanto sujeitos de direito, precisam ter acesso a partir de atividades coerentes com suas características e com as especificidades da infância.

Partindo desses pressupostos, foi desenvolvido um estudo de caso com uma turma de Educação Infantil que atendia crianças de 5 anos, o qual pretendia perceber o desenvolvimento das noções espaciais nas crianças pesquisadas a partir da brincadeira da "Caça ao tesouro", que se caracterizou por um trajeto dirigido desencadeado pelo jogo simbólico (história da "Caça ao tesouro no Sítio”).

Os dados produzidos nesta intervenção, para fins de análise, foram organizados em um episódio que, por sua vez, foi dividido em cenas.

Diante da análise do referido episódio e tendo em vista a pergunta norteadora desta investigação, percebemos que, nessa turma de Educação Infantil, as crianças mobilizaram noções de posição, direção e sentido para participarem da atividade, ampliaram sua percepção do espaço ao apropriarem-se dos pontos de referência, orientando-se a partir deles, manifestando-se, principalmente, através da oralidade e de gestos e ampliando suas possibilidades de representação do espaço.

Tendo em vista estas observações, compreendemos que se faz necessário, na turma investigada, uma maior exploração das noções de direção (para frente/para trás) e de sentido (esquerda/direita) para que essas crianças, além de continuarem no movimento de ampliação das noções de espaço, também compreendam as ações que executam na relação ao mesmo, conseguindo, ainda, nomeá-las adequadamente.

Destacamos nesse ponto o importante papel da linguagem como artefato mediador de 
aprendizagens, pois ela auxilia no processo de generalização dos conhecimentos. Especificamente quando nos referimos à exploração da linguagem matemática, consideramos que é primordial para as crianças nomear objetos, situações ou ações, para assim, melhor compreendê-los e representá-los.

Mediante aos pressupostos teóricos adotados e da análise do episódio aqui apresentada, acreditamos que ao propormos a brincadeira da "Caça ao tesouro", desencadeada pela contação de histórias, possibilitamos às crianças uma exploração planejada do espaço, sem, contudo, cerceá-las, neste processo, de suas especificidades infantis. Mas, pelo contrário, valorizando-as e potencializando-as, através do movimento e do jogo simbólico.

Ainda com relação à brincadeira desenvolvida, temos duas observações a destacar. A primeira diz respeito às crianças, pois consideramos que, para que elas possam desenvolver noções espaciais e criar representações mentais das mesmas, precisam vivenciar o espaço e isso só acontecerá a partir da exploração e através do movimento, ou seja, a partir do corpo e do seu deslocamento no espaço.

A segunda diz respeito ao papel do professor que, para além de oportunizar atividades que promovam essa exploração, deve atuar sempre reavaliando as atividades desenvolvidas, questionando se elas atingiram ou não os objetivos para os quais foram planejadas. Na cena dois, por exemplo, ao desenvolver a atividade, percebemos que uma das orientações no mapa não foi compreensível para as crianças (local próximo ao baú do tesouro, onde as pegadas desenhavam um trajeto circular, retornando posteriormente a direção e o sentido anteriores a esse movimento), mas ao percebermos isso obtivemos elementos para modificarmos outras atividades que tenham propostas semelhantes.

Dessa maneira, as reflexões suscitadas por esse trabalho, considerando o movimento das crianças na mobilização e ampliação das noções espaciais através da brincadeira, indicam, a nosso ver, possibilidades apresentadas pela valorização das experiências e saberes das crianças, potencialidades do lúdico como mediador de aprendizagens e a necessidade da intencionalidade e avaliação reflexiva no trabalho do professor da Educação Infantil. 
ARAUJO, E. S. Matemática e Infância no "Referencial Curricular Nacional para a Educação Infantil": um olhar a partir da teoria histórico-cultural. n. 33. ZETETIKÉ -FE Unicamp - v. 18, 2010.

ELKONIN, D. Problemas psicológicos del juego en la edad preescolar. En: M. Shuare (Comp.), La Psicología Evolutiva y Pedagógica en la URSS. Antología. Moscú. Progreso, 1987.

GONZÁLEZ REY, F. L. Pesquisa Qualitativa e Subjetividade: os processos de construção da informação. São Paulo: Cengage Learnig, 2010.

LANNER DE MOURA, A. R. A medida e a criança pré-escolar. Tese de doutorado. Universidade Estadual de Campinas. Campinas, 1995.

LEONTIEV, A. N. Os princípios psicológicos da brincadeira pré-escolar. In: VIGOTSKII, L.S.; LURIA, A. R.; LEONTIEV, A. N. Linguagem, desenvolvimento e aprendizagem. São Paulo: Ícone, 1991.

Uma contribuição à teoria do desenvolvimento da psique infantil. In: VIGOTSKII, L.S.; LURIA, A. R.; LEONTIEV, A. N. Linguagem, desenvolvimento e aprendizagem. São Paulo: Ícone, 1991a.

LURÇAT, L. El niño y el espacio: la función del cuerpo. México, Fondo de Cultura Económica, 1979.

MOURA, M. O. de. Matemática na Infância. IN: MIGUEIS, M. da R., AZEVEDO, M. da G.. Educação matemática na infância: abordagens e desafios. Gaia: Gailivro, 2007.

(org.) Atividade pedagógica na teoria Histórico-Cultural. Brasília: Liber livro, 2010.

STAKE, R. E. A arte de investigação com estudos de caso. Lisboa: Gulbenkian, 2012.

VIGOTSKI, L. S. A formação social da mente: o desenvolvimento dos processos psicológicos superiores. São Paulo: Martins Fontes, 2007.

WALLON, H. Psicologia e educação da infância. Editorial Estampa, Lisboa, 1975. Evolução psicológica da criança. São Paulo: Martins Fontes, 1981. 